\title{
PEMBUATAN DAN KARAKTERISASI BAHAN ORGANIK BERBASIS TTF DENGAN AKSEPTOR TCNQ DAN $\operatorname{RbZn}(\mathrm{SCN})_{4}$
}

\author{
EVAN MULYANA ${ }^{1}$, NADYA LARASATI K. ${ }^{1}$, THORIQ S. RAHMAN ${ }^{1}$, LUSI SAFRIANI $^{1}, \mathrm{H}$. \\ TANIGUCHI $^{2}$, RISDIANA $^{1 *}$ \\ ${ }^{I}$ Departemen Fisika, FMIPA, Universitas Padjadjaran \\ Jl. RayaBandung-Sumedang Km.21 Jatinangor 45363, Sumedang, Jawa Barat, Indonesia \\ ${ }^{2}$ Department of Physics, Graduate School of Science and Engineering Saitama University, Japan, \\ 255 Shimo-Okubo, Sakura-ku, Saitama City, \\ Saitama 338-8570, JAPAN \\ *email risdiana@phys.unpad.ac.id
}

\begin{abstract}
Abstrak. Telah disintesis bahan organik yaitu TTF-TCNQ dan $\theta$-(BEDT$\mathrm{TTF})^{2} \mathrm{RbZn}(\mathrm{SCN}) 4$ dengan metode difusi untuk kristal TTF-TCNQ dan metode elektrokimia untuk kristal $\theta$-(BEDT-TTF $)_{2} \mathrm{RbZn}(\mathrm{SCN})_{4}$. TTF-TCNQ merupakan kristal yang di dalamnya terjadi charge transfer yang dapat mengalami penurunan resistivitas ketika suhunya diturunkan. Sedangkan kristal $\theta$-(BEDT-TTF) $)_{2} \mathrm{RbZn}(\mathrm{SCN})_{4}$ adalah kristal yang mengalami perubahan sudut $\theta$ yang mengakibatkan terjadinya kenaikan nilai resistivitas secara signifikan pada suhu tertentu.
\end{abstract}

Kata kunci : Bahan Organik, Resistivitas, TTF-TCNQ, $\theta-(\mathrm{BEDT}-\mathrm{TTF})_{2} \mathrm{RbZn}(\mathrm{SCN})_{4}$

Abstract. Organic materials of TTF-TCNQ and $\theta$-(BEDT-TTF) $)_{2} \operatorname{RbZn}(\mathrm{SCN})_{4}$ have been prepared by diffusion and electrochemichal method, respectively. TTF-TCNQ has charge transfer phenomena similar with that of metallic behavior. Resistivity of TTFTCNQ decreased with decreasing temperatures. In another side, resistivity of $\theta$-(BEDT$\mathrm{TTF})_{2} \mathrm{RbZn}(\mathrm{SCN})_{4}$ increased with decreasing temperature due to the changes of angle of $\theta$ in their crystal structure.

Keywords : Organic Materials, Resitivity, TTF-TCNQ, $\theta-(\mathrm{BEDT}-\mathrm{TTF})_{2} \mathrm{RbZn}(\mathrm{SCN})_{4}$

\section{Pendahuluan}

Setiap bahan memiliki kemampuan tertentu dalam menghantarkan arus listrik. Berdasarkan kemampuan menghantarkan arus listrik ini, bahan dapat dikelompokan menjadi isolator, semikonduktor, konduktor dan superkonduktor. Superkonduktor adalah bahan yang dapat mengalirkan arus listrik tanpa adanya hambatan pada suhu yang sangat rendah. Karakteristik yang dapat dihasilkan dari superkonduktor adalah hilangnya hambatan listrik di bawah suhu yang dikenal sebagai suhu kritis (Tc) [1]. Penelitian mengenai bahan superkonduktor ini masih terus dilakukan agar bahan ini dapat diaplikasikan dalam berbagai bidang kehidupan sehari-hari baik di bidang transportasi, komunikasi, alat-alat untuk pengobatan, dan bidang lainnya. Hingga saat ini beberapa peneliti masih mencari superkonduktor yang memiliki Tc tinggi, terutama pada suhu ruang.

Pada awalnya, bahan yang digunakan untuk pembuatan superkonduktor berasal dari komposisi bahan dasar anorganik, yaitu bahan yang berasal dari logam murni 
serta bahan campuran logam dan keramik oksida [1]. Seiring dengan penelitian yang terus berlanjut, superkonduktor ternyata tidak hanya dapat dibuat dari bahan dasar senyawa anorganik tetapi dapat pula dibuat dari bahan dasar senyawa organik. Bahan organik pada umumnya bersifat isolator sehingga tidak memiliki sifat konduktivitas yang baik. Namun, pada tahun 1973 McCoy dan Moore menunjukkan dalam penelitiannya bahwa di dalam bahan organik terdapat radikal atau elektron tidak berpasangan yang dapat bersifat logam tanpa harus menghadirkan atom logam ke dalamnya [2]. Oleh karena itu, tidak menutup kemungkinan bahwa bahan organik bisa dijadikan sebagai bahan superkonduktor yang memiliki nilai konduktivitas tinggi.

\section{Metode Penelitian}

\subsection{Alat dan Bahan TTF-TCNQ}

Alat-alat yang digunakan dalam proses sintesis ini adalah neraca ohaus, elektrolisis sel/ H-cube, fiber glasses, pinset, kertas saring dan kertas timbangan. Sedangkan bahan-bahan yang digunakan dalam sintesis krital TTF-TCNQ adalah TTF (50 mg), TCNQ (50 mg) dan $\mathrm{CH}_{3}-\mathrm{CN}$ dengan banyak disesuaikan dengan kondisi elektrolisis sel yang digunakan (kondisi di mana fiber glasess kiri dan kanan terendam). Kemudian, meletakan fiber glasses di bagian kiri, kanan dan tengah elektrolisis sel. digambarkan pada Gambar 1. Proses pencampuran bahan ini diawali dengan mencampurkan TTF di bagian diameter yang sempit pada elektrolisis sel dan TCNQ di bagian diameter yang lebih luas.Kemudian, melarutkan $\mathrm{CH}_{3}-\mathrm{CN}$ ke dalam elektrolisis sel sampai batas rongga yang terhubung (di bagian atas pada elektrolisis sel). Rongga terhungung pada bagian atas elektrolisis sel ini berfungsi agar tekanan dalam elektrolisis pada bagian kiri dan kanan memiliki nilai yang sama. Pada saat pelarut $\mathrm{CH}_{3}-\mathrm{CN}$ dimasukkan ke dalam elektrolisis sel secara perlahan TTF dan TCNQ akan larut dan mengalami proses difusi.

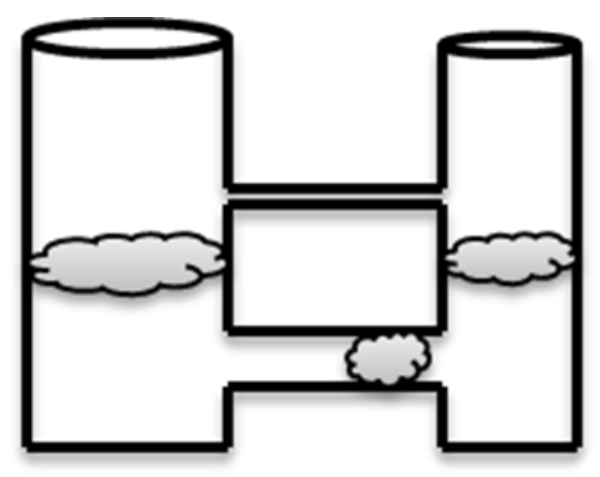

Gambar 1. Peletakan fiber glasses pada elektrolisis sel

\subsection{Metode Eksperimen TTF-TCNQ}

Metode difusi merupakan metode yang digunakan dalam penelitian ini, di mana di dalamnya terjadi perpindahan zat dalam pelarut dari bagian konsentrasi tinggi ke konsentrasi rendah. Proses isolasi larutan yang telah dicampurkan dalam elektrolisis sel dilakukan pada suhu ruang selama 3 hari. Kondisi ini merupakan kondisi ideal di mana kristal akan tumbuh sesuai dengan yang diharapkan. Pada 
saat proses isolasi dilakukan proses pengontrolan agar setiap kejadian yang terdapat pada proses isolasi dapat teramati. Kemudian, setelah proses isolasi selesai dilanjutkan denganmengeluarkan semua fiber glasses yang terdapat di dalam elektrolisis sel secara hati-hati (jangan sampai kristal yang terbentuk pecah). Proses selanjutnya,mencuci fiber glasses menggunakan diethyl ether (fiber glasses diletakan di atas kertas saring yang dilipat membentuk kerucut disimpan di atas tabung erlenmeyer). Proses pencucian dari fiber galsses ini dilakukan di ruang asam. Tahapan terkahir dari proses sintesis ini adalah pick-up kristal dari fiber glasses. Proses pick-up kristal dilakukan dengan bantuan alat berupa pinset, kayu tipis dan kertas saring sebagai tempat kristal yang telah dipick-up. Proses pick-up kristal ini memerlukan waktu sekitar 2-3 jam atau bahkan bisa lebih, tergantung pada seberapa banyak krsital yang menempel pada fiber glasses. Di dalam proses ini, tidak semua kristal dilepaskan dari fiber glasses, tetapi dipilih krista-kristal yang memang memenuhi kriteria ideal. Setelah proses pengambilan kristal selesai, maka kristal telah siap untuk proses karakterisasi.

\subsection{Alat dan Bahan $\theta-(B E D T-T T F)_{2} \operatorname{RbZn}(\mathrm{SCN})_{4}$}

Alat-alat yang digunakan pada metode elektrokimia ini adalah neraca ohaus, tabung erlenmeyer, magnetic stirrer, elektrolisis sel, pinset, kertas saring, kertas timbangan, alumunium foil dan inkubator.Bahan-bahan yang digunakan untuk mensistesis $\theta$-(BEDT-TTF) ${ }_{2} \mathrm{RbZn}(\mathrm{SCN})_{4}$ adalah BEDT-TTF $(10 \mathrm{mg}), \mathrm{RbSCN}(25$ $\mathrm{mg}$ ), $\mathrm{Zn}(\mathrm{SCN}) 210 \mathrm{mg}, 1.1 .2-\mathrm{TCE}$ (Trikoloro etilen) $23 \mathrm{ml}$ dan Etanol (2 ml). Bahan-banah tersebut dicampurkanke dalam tabung erlenmeyer. Kemudian, melarutakan 1.1.2-TCE (trikoloro etilen) dan Etanol ke dalam tabung erlenmeyer. Campuran tersebut kemudian dihomogenkan/diratakan menggunakan magnetik stirrer (selama 24 jam) dan menutup tabung erlenmeyer menggunakan alumnium foil. Penggunaan alumunium foil ini dilakukan karena larutan sensitif terhadap cahaya dari lampu yang terdapat di laboratorium.

\subsection{Metoda Eksperimen $\theta$-(BEDT-TTF $)_{2} \operatorname{RbZn}(\mathrm{SCN})_{4}$}

Metode eksperimen yang digunakan adalah metode elektrokimia. Proses ini diawali dengan meletakan larutan dari tabung erlenmeyer ke dalam elektrolisis sel menggunakan kertas saring. Meletakkan elektroda pada bagian sisi kiri dan kanan elektrolisis sel dan rapatkan elektroda menggunakan parafilm.Kemudian, larutan dimasukkan ke dalam inkubator. Gambar 2 menunjukkan alat (inkubator) yang digunakan untuk sintesis $\theta$-(BEDT-TTF $)_{2} \operatorname{RbZn}(\mathrm{SCN})_{4}$ beserta keadaan pemasangan arus listrik di dalam alat. Proses elektrolisis dalam inkubator dialirkan arus sebesar $0,5 \mu \mathrm{A}$, resistansi $10 \mathrm{k} \Omega$ dan suhu inkubator $30^{\circ} \mathrm{C}$ (proses ini dilakukan selama 10 hari). Dalam proses selama 10 hari dilakukan pengontrolan guna mengetahui kejadian yang terdapat dalam proses elektrokimia ini.Proses elektrokimia selesai dengan menghentikan arus yang mengalir pada elektrolisis sel. Selanjutnya, mengambil kristal-kristal yang tumbuh pada elektroda dan pada elektrolisis sel. Proses ini diawali denganmeletakan kertas saring di atas tabung erlenmeyer.Mengambil kristal yang terdapat di dalam elektroda dengan memindahkan larutan yang membasuh elektroda ke dalam tabung erlenmeyer sampai kristal jatuh pada kertas saring. Tahapan terakhir adalah mencuci kristal menggunakan diethyl ether dan mengeringkannya selama 2 jam. Proses pengambilan kristal-kristal pada elektrodan dan pada elektrolisis sel dilakukan di ruang asam. 


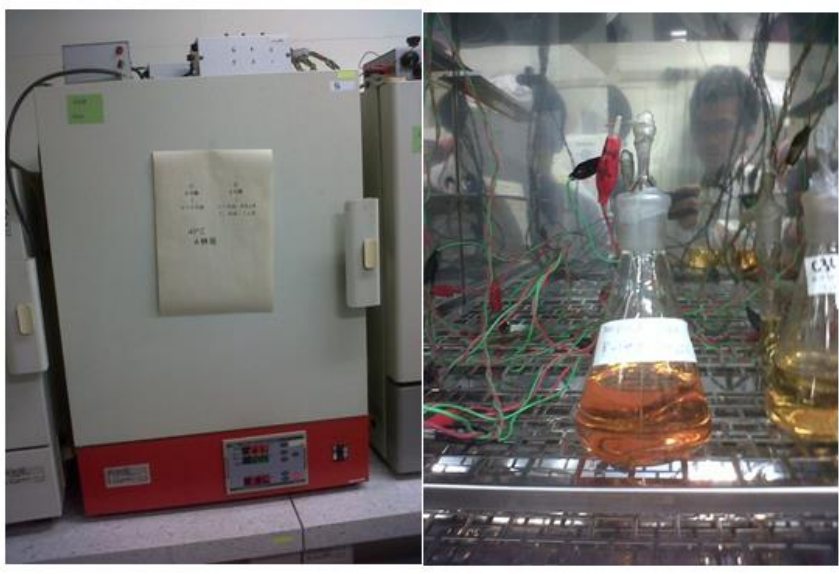

(a)

(b)

Gambar 2. (a) Inkubator (Tampak luar) (b) Keadaan pemasangan arus listrik di dalam inkubator

\subsection{Karakterisasi}

Pemasangan kawat Au ini digunakan metode four point probe, yaitu meletakan empat kawat Au pada kristal. Kawat Au yang digunakan diameternya berukuran $25 \mu \mathrm{m}$. Perekat yang digunakan dalam proses ini adalah pasta karbon. Alat bantu yang digunakan dalam metode ini adalah pinset dan tusuk gigi yang ditempeli bulu mata untuk menggeser kristal, serta mikroskop cahaya sebagai alat pembesaran kristal. Proses ini dilakukan dalam waktu 1-2 hari sampai kawat terpasang pada kristal dengan baik, artinya pasta karbon yang digunakan tidak saling bersentuhan satu sama lain agar tidak terjadi koneksi satu sama lain. Dalam proses pemasangan kawat pada kristal ini, sebelumnya dilakukan pemilihan kristal yang ideal guna mempermudah peletakan kawat $\mathrm{Au}$ pada kristal. Proses ini dilakukan pada beberapa kristal, hal ini dilakukan karena apabila terjadi patahan pada satu kristal ketika proses karakterisasi, maka dapat digunakan kristal yang lainnya.

Identifikasi nilai resistivitas dilakukan dalam beberapa tahapan, yaitu:

a. Meletakan kristal yang telah dipasangkan kawat Au pada base. Gambar 3 menunjukkan cara peletakan kristal yang dipasangkan pada base. Kawat $\mathrm{Au}$ yang telah diletakan pada masing-masing kristal dihubungkan pada ujung-ujung base yang konduktif. Kemudian, direkatkan kembali menggunakan pasta karbon.

b. Meletakkan base pada probe yang dihubungkan pada alat untuk pengukur resistivitas dan komputer untuk melihat hasil grafik penurunan suhu terhadap resistansi.

c. Kemudian masukan nitrogen cair secara perlahan (dalam hal ini harus menjaga nilai penurunan suhu pada kristal turun $1 \mathrm{~K} /$ menit). Pengerjaan ini dilakakukan selama \pm 3 jam mulai dari suhu $300 \mathrm{~K}-77 \mathrm{~K}$. Untuk menjaga agar penurunan suhu tetap turun sebesar $1 \mathrm{~K} /$ menit dilakukan dengan dua cara, yaitu memasukkan kembali nitrogen cair ke dalam dewer dan menurunkan probe yang telah dimasukan dalam dewer. Tahapan akhir dari proses karakterisasi ini adalah pengamatan nilai resistivitas terhadap penurunan suhu. 


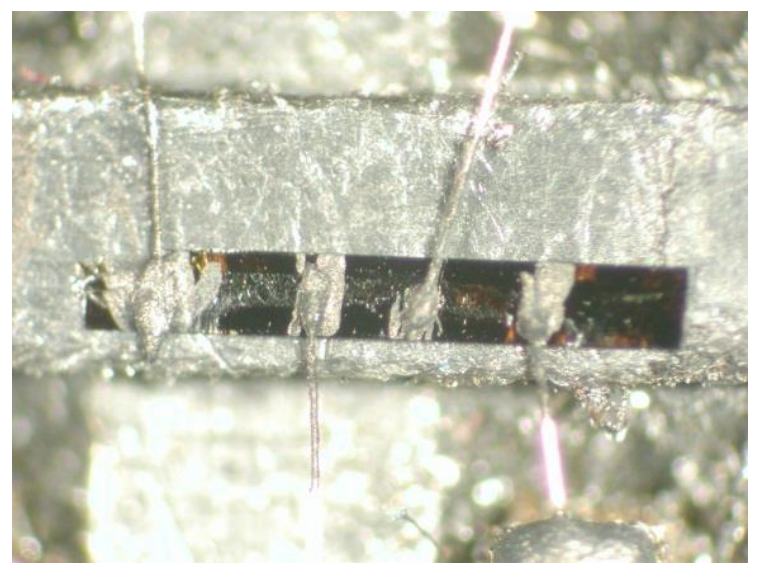

Gambar 3. Peletakan kawat Au pada kristal TTF-TCNQ

Metode Four Point Probe, yaitu metode pemasangan kawat konduktor pada kristal untuk mempermudah proses karakterisasi, yaitu mengidentifikasi nilai resistivitas. Kawat-kawat yang diletakan pada kristal ini terdiri atas 4 kawat yang memiliki fungsi untuk menghubungkan kristal dengan arus dan tegangan yang akan diberikan pada kristal. Pemasangan kawat Au ini biasanya dilapisi oleh pasta konduktor sebagai perekat. Salah satu contoh pasta yang digunakan dalam metode ini adalah pasta karbon. Gambar 3 menunjukkan penghubungan arus listrik dan tegangan dengan kristal.Proses peletakan kawat Au pada kristal tidak boleh saling menyentuh satu sama lain agar tidak terjadi koneksi antara kawat Au yang satu dengan yang lain. Untuk memudahkan pemasangan kawat $\mathrm{Au}$, maka diperlukan kristal yang besar dan dimensi yang baik. Pada Gambar 3 juga dijelaskan bagaimana kawat posisi kawat diletakkan pada kristal.

Adapun perhitungan nilai resistivitas dapat dihitung dengan rumus :

$$
\begin{array}{r}
R=\rho \frac{L}{A} \\
\rho=\frac{R \times A}{L} \\
\rho=\frac{R \times a \times b}{d}
\end{array}
$$

dengan :

$\mathrm{a}=$ Tebal kristal $(\mu \mathrm{m}) ; \mathrm{b}=$ Lebar kristal $(\mu \mathrm{m}) ; \mathrm{c}=$ Panjang kristal $(\mu \mathrm{m}) ; \mathrm{d}=$ Jarak antara kawat kedua dan ketiga $(\mu \mathrm{m})$ dan $\rho=\operatorname{Resistivitas}(\Omega \mathrm{m})$

Perhitungan nilai resistivitas ini dimaksudkan agar diketahui bagaimana karakteristik kristal jika dilihat dari perubahan nilai resistivitasnya. Perubahan nilai resistivitas ini seiring dengan perubahan penurunan suhu yang diaplikasikan pada kristal. 


\section{Hasil dan Pembahasan}

Gambar 4 menunjukkan hasil sintesis kristal TTF-TCNQ sebelum dilakukan pickup (pengambilan) Kristal.Hasil dari sintesis kristal ini didapat beberapa kristal yang memenuhi kriteria kristal ideal, yaitu tidak ada retakan, ukurannya besar, tidak terjadi tumpang tindih antara kristal yang satu dengan yang lainnya dan memiliki ukuran dimensi yang baik untuk mempermudah pengukuran geometri kristal.

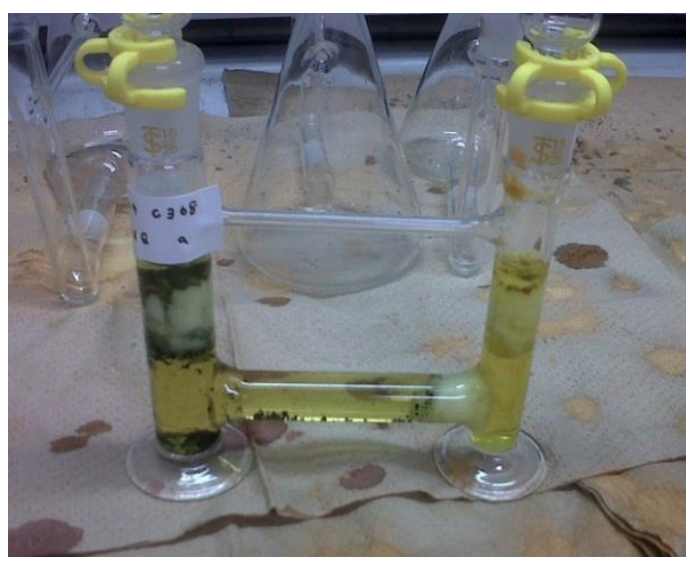

Gambar 4. Hasil sintesis kristal TTF-TCNQ

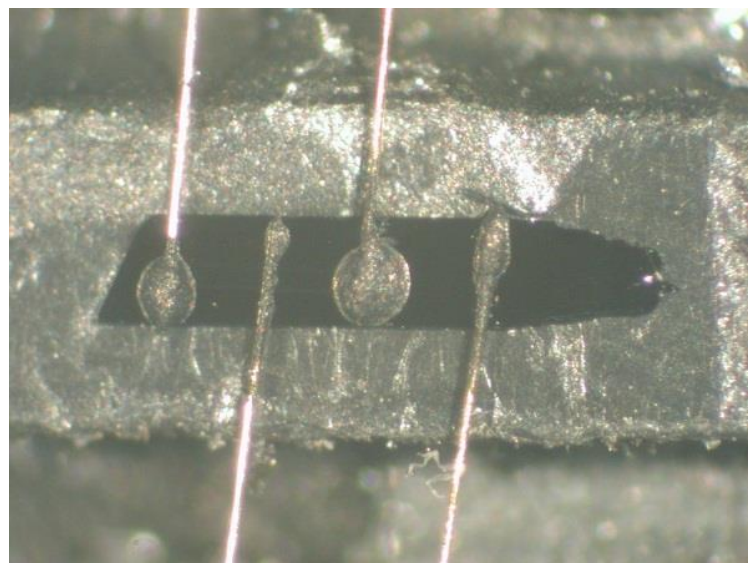

Gambar 5. Hasil Pemasangan kawat Au pada kristal

Pada Gambar 5 memperlihatkan hasil pemasangan kawat pada kristal yang akan dikarakterisasi. Terlihat bahwa karbon pasta yang ditempelkan pada kristal tidak menyentuh dengan karbon pasta pada kristal di sebelahnya, agar tidak terjadi koneksi saat pemberian arus listrik. Ukuran kristal pada Gambar 5 yaitu :
a (tebal kristal)
$: 50 \mu \mathrm{m}$
b (lebar kristal)
$: 165 \mu \mathrm{m}$
c (panjang kristal)
$: 1.175 \mu \mathrm{m}$
d (jarak kawat kedua dan ketiga)
$: 225 \mu \mathrm{m}$ 
Pada Gambar 6 menunjukkan hasil karakterisasi [Grafik resistivitas $(\rho)$ terhadap suhu $(\mathrm{T})$ dan Grafik konduktivitas $(\sigma)$ terhadap suhu $(\mathrm{T})]$ kristal TTF-TCNQ. Grafik hasil eksperimen menunjukkan bahwa nilai resistivitas menurun terhadap penurunan suhu. Pengamatan penurunan suhu ini dilakukan mulai dari suhu sebesar 299,984K sampai 77,799K. Ketika grafik dirubah menjadi grafik penurunan konduktivitas terhadap suhu, maka nilai konduktivitas akan mengalami kenaikan seiring dengan penurunan suhu. Seperti diketahui bahwa memang resistivitas berbanding terbalik dengan konduktivitas. Kristal TTF-TCNQ ini juga bersifat sebagai half metal, yaitu zat yag dapat bersifat sebagai konduktor pada suatu orientasi spin dan dapat sebagai isolator atau semikonduktor pada orientasi spin yang berlawan.
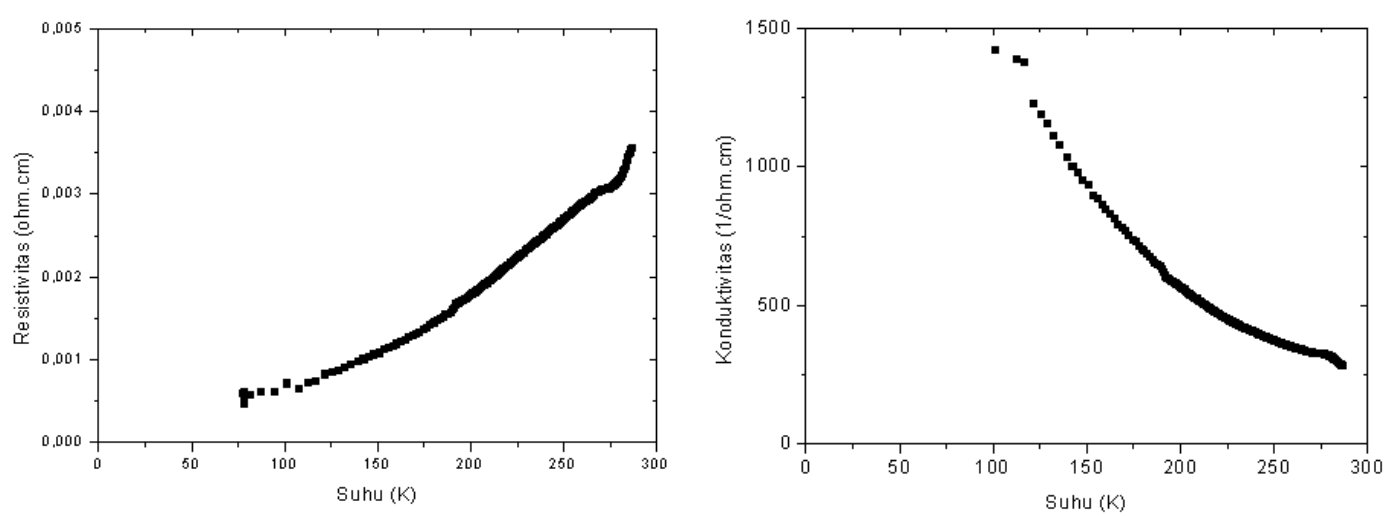

Gambar 6. (a)Grafik resistivitas terhadap penurunan suhu.(b) Grafik konduktivitas terhadap suhu untuk TTF-TCNQ

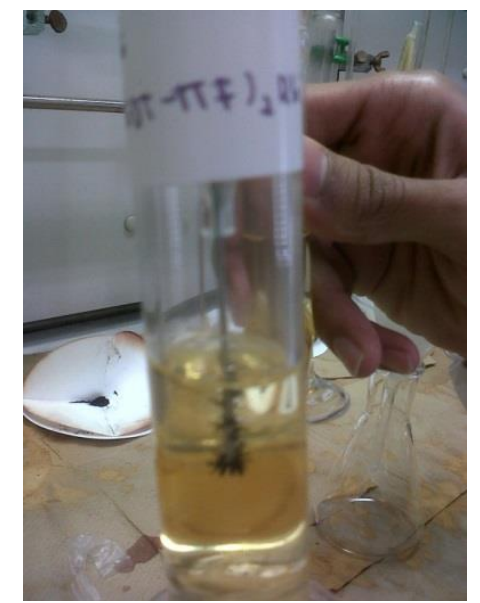

Gambar 7. Hasil Pemasangan kawat Au pada kristal

Didapat kristal $\theta$-(BEDT-TTF $)_{2} \mathrm{RbZn}(\mathrm{SCN})_{4}$ seperti pada Gambar 7. Dari kristalkristal ini dipilih kembali kristal yang sangat mendekati kriteria ideal untuk dikarakterisasi. Ukuran kristal yang dihasilkan ini adalah :
a (tebal kristal)
$: 50 \mu \mathrm{m}$
b (lebar kristal)
$: 220 \mu \mathrm{m}$ 


$$
\begin{array}{ll}
\mathrm{c} \text { (panjang kristal) } & : 1.110 \mu \mathrm{m} \\
\mathrm{d}(\text { jarak antara kawat kedua dan ketiga) } & : 200 \mu \mathrm{m}
\end{array}
$$

Grafik hasil eksperimen menunjukkan bahwa RbZn mengalami proses charge ordering, yaitu adanya kenaikan nilai resistivitas secara signifikan. Keadaan ini secara teoritik ditandai dengan adanya perubahan sudut $\theta$. Kenaikan nilai resistivitas secara drastis ini ditunjukkan pada suhu $170 \mathrm{~K}$, di mana proses ini menunjukkan bahwa sudut $\theta$ mengalami peningkatan seiring penurunan suhu. Peningkatan nilai sudut $\theta$ mengakibatkan struktur kristal akan membentuk keadaan kristal satu dimensi, sehingga kristal akan bersifat sebagai insulator. Apabila sudut $\theta$ menurun, maka kristal akan membentuk struktur dua dimensi yang akan mengakibatkan kristal kemungkinan bersifat sebagai superkonduktor. Pada Gambar 8 menunjukkan (a) Grafik resistivitas terhadap penurunan suhu,(b) Grafik Logaritmik resistivitas terhadap suhu untuk $\theta$-(BEDTTTF) ${ }_{2} \mathrm{RbZn}(\mathrm{SCN})_{4}$.
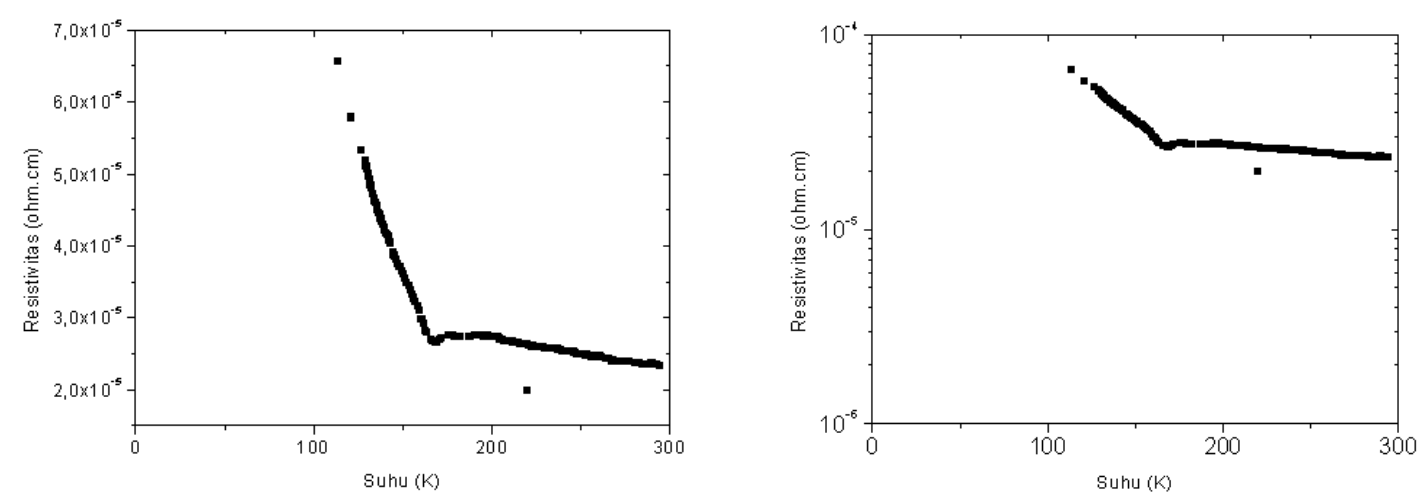

Gambar 8. (a) Grafik resistivitas terhadap penurunan suhu (b) Grafik Logaritmik resistivitas terhadap suhu untuk $\theta$-(BEDTTTF)2RbZn(SCN)4

\section{Kesimpulan}

Berdasarkan analisa dan pembahasan data hasil penelitian maka didapat kesimpulan:

1. Telah berhasil dibuat kristal TTF-TCNQ dengan metode difusi dan didapat ukuran geometri kristal, tebal (a) $=50 \mu \mathrm{m}$, lebar (b) $=165 \mu \mathrm{m}$, panjang (c) $=1.175 \mu \mathrm{m}$ dan jarak antara kawat kedua dan ketiga $(\mathrm{d})=225 \mu \mathrm{m}$. Morfologi kristal yang dihasilkan sebagian besar mendekati kristal ideal. Kristal TTF-TCNQ yang dihasilkan dari penelitian ini memiliki nilai konduktivitas yang meningkat terhadap perubahan penurunan suhu. Proses ini menunjukkan kristal TTF-TCNQ bersifat sebagai half metal.

2. Telah berhasil dibuat kristal $\theta$-(BEDT-TTF $)_{2} \mathrm{RbZn}(\mathrm{SCN})_{4}$ dengan metode elektrokimia dan didapat ukuran geometri kristal, tebal (a) $=50 \mu \mathrm{m}$, lebar (b) $=220 \mu \mathrm{m}$, panjang (c) $=1.110 \mu \mathrm{m}$ dan jarak antara kawat kedua dan ketiga $(\mathrm{d})=200 \mu \mathrm{m}$. Morfologi kristal yang dihasilkan sebagian besar mendekati kristal ideal. Kristal $\theta$-(BEDT-TTF $)_{2} \operatorname{RbZn}(\mathrm{SCN})_{4}$ mengalami kenaikan nilai resistivitas secara signifikan yang diakibatkan oleh adanya peningkatan sudut $\theta$ pada saat penurunan suhu. Proses ini menunjukkan bahwa kristal $\theta$-(BEDT-TTF $)_{2} \mathrm{RbZn}(\mathrm{SCN})_{4}$ bersifat sebagai insulator. 


\section{Ucapan terima kasih}

Penulis menyampaikan rasa terima kasih dengan tulus atas dukungan dana dari Kanryu Program Saitama University serta seluruh anggota Taniguchi's Lab diantaranya Sakate Daisuke, Yoshiko Tsukiyama, Noriaki Okabe, serta Andria Kurniawan selaku pembimbing dan sahabat saya selama penelitian dan berada di Saitama University, Jepang.

\section{Daftar Pustaka}

1. A. Mourachkine, 2003, Room Suhue Superconductivity, Cambridge International Science Publishing, Inggris.

2. W. Deprophetis, 2002, Organic Superconductors,Jurnal Thrid Year Seminar.

3. Susan A. Odom, dan tim, 2010, Restoration of Conductivity with TTF-TCNQ Charge-Transfer Salts, International Science Publishing, Inggris.

4. Satoshi Miyashita dan Kenji Yonemitsu, 2008, Charge ordering in (BEDT TTF)2RbZn(SCN)4: Cooperative effects of electron correlations and lattice distortions, Institute for Materials Research, Tohoku University, Jepang.

5. A. Andrieux, H. J. Schulz, D. Jerome, Fluctuation Conductivity in 1-D Conductor TTF-TCNQ, Paris-Sud University. Paris.

6. Yamamoto, et al, 2006, Dielectric response in the charge-ordered $\theta$-(BEDTTTF)2RbZn(SCN)4 organic compound,Hirosawa Wakoshi, Saitama, Jepang.

7. H. Alves, et al, Metallic Conduction at Organic Charge-Transfer Interfaces, Kavli Institute of Nanoscience, Delft University of Technology, Lorentzweg 1, 2628 CJDelft, Belanda 